\title{
Secondary school teachers' attitude to mental illness in Ogun State, Nigeria
}

\section{NC Aghukwa}

Department of Psychiatry, Aminu Kano Teaching Hospital, Bayero University, Kano, Nigeria

\begin{abstract}
Objective: Teachers as role models stand in a unique position in the formation of their pupils' set values about mental health issues. The aim of this study therefore was to determine the attitude of teachers to mental illness. Method: The questionnaire for the study was a drafted modified self-administered one, distributed among a randomly selected sample of teachers in the area of study. Results: A significant number of teachers would not want to interact with former mentally ill persons in close social situations and many of them felt such people were unpredictable. Most of the respondents would not want former mentally ill persons holding sensitive jobs. More years of teaching was associated with not perceiving the former mentally ill person as being unpredictable. Teachers' highest educational qualification significantly related to their attitude towards former mentally ill persons. More teachers with Master's Degree than those with N.C.E qualification would not mind employing former mentally ill persons as gardeners, likewise not perceiving them as unpredictable or dangerous to other people in their surroundings. Results of the study showed that the majority of the teachers expressed negative attitudes in close social situations and job entrustments towards former mentally ill persons. Conclusion: Mental health educational programmes geared towards a change in teachers' preconceptions about mental illness and with opportunities for positive interactions with mentally ill persons might be effective in changing their negative attitude towards former mentally ill persons.
\end{abstract}

Key words: Teachers; Attitude; Mental Illness

Received: 08-05-2008

Iccepted: 23-07-2008

\section{Introduction}

The Nigerian public judges the seriousness of mental illness mainly on behavioural grounds. ${ }^{1}$ Due to this the public sees the mentally ill as dangerous, often, looked at with disfavor and as people not to interact with in close social situations. ${ }^{1,2}$ This perception of the mentally ill worsens their burden: firstly the burden of the symptoms and disabilities that result from the disease and secondly, the consequence of the public's ill judged beliefs about the illness. Corrigan and Penn ${ }^{3}$ commented that discriminatory behaviors arise due to the public's poor understanding of mental illness. Because of this, they miss opportunities that define quality of life, such as good jobs, safe housing, and satisfactory health care and affiliation

\section{Correspondence:}

with a diverse group of people. In addition, the publics' inaccurate belief that mental illness is incurable heightens the perceived fear towards patients thereby worsening the stigma and prejudice they encounter. ${ }^{4}$

Internationally, the World Psychiatric Association (WPA) has embarked on programmes to fight the stigma and discrimination associated with mental illness. ${ }^{5}$ They utilized three approaches, viz: Protest, Contact and Education. Education plays a very crucial role in national development in many developing countries such as Nigeria. Studies have shown that discrimination against the mentally ill is equally common among younger people as in adults. ${ }^{6}$ This suggests that one important place to fight for a change in attitude should be within schools. The psychological sophistication of teachers is important in modifying histher pupils' personality in a manner that fosters growth. ${ }^{7}$ Teachers as a group encounter all schoolchildren, but as suggested by Jegede ${ }^{7}$, they are no better than the parents and their school-going children in their understanding of mental health principles. A study of the attitude of Secondary school teachers to mental 
illness and the mentally ill might highlight the need for interventions aimed at changing the teachers' attitude towards mentally ill people.

\section{Method}

\section{Design \& Setting}

The study was prospective and cross Sectional. The study was underatken in Ogun State, one of the 36 States in the Federation of Nigeria. The State has twenty Local Governments one of which is Abeokuta South Local Government from where the study population came. There are 20 public Secondary Schools (17 co-educational, 2 girls' only and one boys only) with 21,896 students enrolled and 1003 teachers of whom 401 and 602 were males and females respectively. The twenty schools were within the metropolis.

\section{Sample size and sampling technique}

A computed minimum sample size of 325 was required based on the assumption of 50\% knowledge levels at $95 \%$ confidence interval and a $4.5 \%$ margin of error. ${ }^{8}$ An additional number of $33(10 \% \text { of the deduced sample size })^{9}$ were added to have a figure of 358. By this, incompletely filled questionnaires did not affect the required number of correctly filled ones for analysis The twenty schools in the Local Government Area were subjected to a stratified random sampling procedure with proportionate allocation to each stratum for "type of school" (co-educational (803), boys (58) and girls' only (115)). Therefore, $85 \%$ of the deduced sample size came from five of the "co-educational" schools selected by the simple random (lottery) procedure. Ten percent of the sample population came from one of the "girls' only" school and this was selected by a single one time balloting. The rest of the sample population ( $5 \%$ ) was selected from the "boy's only school".

\section{Method of data collection}

An informed consent to conduct the study was obtained from the authorities of the Ogun State Ministry of Education and from both the school principals and the teachers in the selected schools. Both the teachers' and the principal in each of the schools for the study gave verbal consent. The teachers had assurance of anonymity of their responses. The teachers in each of the selected schools decided on a convenient day for the questionnaire administration, and on that day, responded to the questionnaire. The teachers dropped the answered questionnaires in a sealed collection box kept at one of the entrances to the staff room.

\section{Instrument for data collection}

Data collection was by a questionnaire, which was a 21 item self-administered questionnaire with sections A-D. The title page contained an introductory statement to the respondents about probably having come across persons with mental illness that is culturally termed madness or "wérè" in the local language. Section. A comprised questions on the respondents' social distancing attitude towards treated mentally ill persons.

The first subsection contained a vignette depicting a treated psychotic female patient. In addition, questions about befriending, working in same office and attending the same club as this person were asked. The questions were to elicit the respondents' opinion on various levels of non-intimate social interaction with the person in the vignette. The next subsection elicited the respondents' opinion on domestic employment of treated mentally ill persons (employee relationship: employing a treated mentally ill person as a gardener and as a baby sitter) while the third subsection elicited the respondents' opinion on closer (intimate relationships) social interactions with them. The questions were: 1) talking to a friend about a relation who is always mentally ill, 2) talking to a friend about a brother/sister who was mentally ill, 3) Considering marrying somebody who had been mentally ill, and 4) Agree to one's child marry a person who had mental illness. Section B contained questions that sought the opinions of the respondents' about a treated mentally ill person being 1) Unpredictable, 2) dangerous to others in his surrounding and 3) dangerous to themselves. These questions were about the potential dangers of treated mentally ill persons and contained a vignette that depicted a treated male police officer. Section $C$ sought the respondents opinion about the occupational potential of treated mentally ill persons such as, 1) serving in the Army, 2) working as Doctors, 3) teacher and 4) serving as the Minister of Education, and 5) the Head of State of the Country. The last section (D) ascertained the respondents' opinion about psychiatric care. This section contained questions that asked questions like: 1) should high walls and guards surround every psychiatric institution, 2) should mental patients be kept permanently in an institution rather than sent home when their condition improves, 3) Do you think that mental patients should be treated in separate psychiatric institutions rather than in a psychiatric department within a general hospital, and 4) Would you encourage a friend or relative to go to a psychiatric hospital if they experienced mental illness.

A pilot study to pre-test the prototype questionnaire was among a selected group of teachers in one of the schools not included in the study. Reliability estimate was by the test-retest method and high levels of positive correlation showed in the positive and negative items response scores between the first test and the retest items after 3 weeks interval. A subjective determination of the content validity was by giving the questionnaire to five Consultant Psychiatrists and a Sociologist for their input. Some necessary revisions and changes were from the outcome of the pilot study.

\section{Data Analysis}

Data analysis was with the Epi-Info-version 6.0 statistical software. ${ }^{10}$ Presentation of data was by using simple frequency distribution tables and absolute numbers and percentages to the nearest tenth to summarize categorical values. Summary statistics (e.g., means, standard deviation) described quantitative variables where appropriate. Tests of associations between the teachers' exposure to knowledge, some sociodemographic variables (such as highest level of education, years of teaching experience) and their responses on the vignettes on mental illnesses were carried out using $\mathrm{X}^{2}$ (Chisquare) test. A p value of $<0.05$ was statistically significant.

\section{Results}

Socio-demographic characteristics of respondents

Three hundred and fifty-eight questionnaires filled by the respondents were collected from seven schools used in the study, out of which three hundred and twenty five (90.8\%) were considered valid and analyzed. The three hundred and twenty- 
five respondents with valid responses represented thirty-three percent $(33 \%)$ of teachers' population in the area of study. One hundred and five (32.3\%) respondents were males, 220 $(67.7 \%)$ were females and this is similar to the $2: 1$ female to male ratio in the population of teachers from the study area. The majority $(n=190 ; 58.5 \%)$ of the respondents had a Bachelor's Degree in Education, $71(21.8 \%)$ had a National Certificate of Education (N.C.E), 38(11.2\%) a Master's Degree and $26(8 \%)$ had Diploma qualifications. One hundred and fifty seven (48.3\%) of them specialized in Basic Sciences. Most ( $n=263 ; 80.9 \%$ ) of the respondents were married and $272(83.7 \%)$ of them belonged to the Christian faith. The mean age of the respondents was 36.8yrs $(+7.2)$ and their mean number of years of teaching was 12.2 years $(+6.92)$. One hundred and seventy eight $(54.8 \%)$ respondents had contact with treated mentally ill persons with acceptable level of appearance and behavior and One hundred and nineteen (36.6\%) had contact with treated mentally ill persons with persistently odd appearance and behavior. Five (2\%) of the teachers had suffered mental illness and Thirty-three (10.2\%) had relations that suffered mental illness. One hundred and seventy five (53.8\%) of them knew of somebody suffering mental illness and One hundred and seventy eight (54.8\%) also knew somebody who had same illness before.

\section{Social acceptance of treated mentally ill persons}

Non-intimate relationships:

Two hundred and thirty seven (73\%) respondents agreed to have a treated mentally ill person teach, $251(77.2 \%)$ agreed to befriend while $248(76.3 \%$ ) and $226(69.5 \%)$ respectively would work in same office and attend the same club as a treated mentally ill person.

\section{Employee relationships}

One hundred and forty six (44.9\%) agreed to employ such persons as gardeners while only $38(11.7 \%$ ) would have them as babysitters.

\section{Intimate relationships.}

One hundred and twenty four (38.2\%) of the respondents would not advice their children against marrying a treated mentally ill person but $52(16 \%)$ could consider marrying such a person while $39(24 \%)$ would agree to their child marrying same persons.

\section{Potential Dangers of a former mentally ill person}

The distribution of responses about the potential dangers of former mentally ill patients among the teachers showed that 175(54\%) respondents felt treated mentally ill persons were dangerous to people in their surroundings. One hundred and sixty six (51.6\%) of them also felt these persons were unpredictable and as such 164(51.4\%) would not want such persons serving in the police force.

\section{Occupational potential of former mentally ill patients}

More than $68 \%$ of teachers did not agree to treated mentally ill persons holding jobs and this was more with such public career jobs as being a Minister ( $n=254 ; 79 \%)$ or the Head of State $(n=286 ; 88.0 \%)$ of the country. Two hundred and seventy three $(84.0 \%)$ and $223(69 \%)$ respectively would not want such persons to serve in the Army or work as medical doctors.
Respondents' opinion about care for the mentally ill person Two hundred and fifty six (79\%) of the respondents felt psychiatric inpatients should be surrounded by high walls and guards, and $248(76 \%)$ felt psychiatric patients should not be kept permanently in an institution. Two hundred and thirty eight $(74 \%)$ were of the opinion that mentally ill patients should be treated in separate institutions than in general hospitals although $310(95 \%)$ would encourage an ill friendirelative to go to a psychiatric hospital for treatment when sick with mental illness.

\section{Associations between Some Socio-demographic variables and teachers' attitude towards mental illness}

Teachers' years of teaching significantly related to their views about the dangerousness of treated mentally ill persons. More teachers who had been longer in service felt less of treated mentally ill persons as been unpredictable $\left(\mathrm{X}^{2}=13.21, \mathrm{df}=4\right.$, $\mathrm{p}=0.039$ )

In the aspect of social interaction with treated mentally ill persons, there was an association between teachers' highest educational qualification and employing these persons as gardener. Twenty-six (72.2\%) of them with Master's qualification agreed to employ such persons as gardener while $47(58.3 \%)$ and $78(41.3 \%)$ respectively of N.C.E and Bachelor's qualified teachers' agreed alike $\left(X^{2}=12.16, d f=3\right.$, $p=0.01)$. Teachers with less than Master's qualification were also more socially distancing i.e. Masters $(n=24 ; 70.6 \%)$, vs N.C.E $(n=66,91.2 \%)\left(X^{2}=10.98, d f=3, p=0.02\right)$. Twenty seven (75\%) and $21(56.3 \%)$ of Masters qualified teachers respectively felt treated mentally ill persons were neither unpredictable nor dangerous to other people in their surroundings, while $63.4 \%(n=45)$ and $67.6 \%(n=48)$ respectively with N.C.E qualification held contrary opinions to the earlier stated $\left(\mathrm{X}^{2}=14.86, \mathrm{df}=3, \mathrm{p}=0.002\right)$ and $(\mathrm{X} 2=8.30$, $\mathrm{df}=3, \mathrm{p}=0.04$ ) respectively.

Significantly more female $(n=189 ; 92.4 \%)$ than male $(n=92 ; 79.3 \%)$ teachers would not agree to their childlchildren marrying former mentally ill persons $\left(\mathrm{X}^{2}=12.46, \mathrm{df}=1\right.$ $\mathrm{p}=0.02)$.

There was no significant association between Age, religion and marital status of the respondents and their attitude towards mental illness ( $\mathrm{P}>0.05)$

\section{Discussion}

3 out of 4 teachers expressed more liberal attitudes in less close social situations with treated mentally ill persons but about 3 out of 4 of the same respondents were more rejecting towards them as the social interaction got closer. About five out of every 10 teacher respondents felt that treated mentally ill persons were unpredictable and dangerous to both self and others around them. 8 out of 10 of same respondents would not want treated mentally ill persons holding such sensitive jobs as being a military personnel and a medical doctor or being the head of state of the nation. Previous studies by Binitie', Odejide and Olatawura ${ }^{11}$ have also claimed that a decreasing number of respondents were willing to interact with mentally ill persons as the social relationship became more intimate. Binitie ${ }^{1}$ claimed that the respondents in his study judged seriousness of mental illness on behavioral grounds. Many felt such persons, as expressed by the majority of the respondents in this study were dangerous and also unkempt and aggressive. However, the 
study by Odejide and Olatawura ${ }^{11}$ also claimed that the effect of the day-to-day interaction of the psychiatric nurses with the mentally ill influenced their attitude towards these persons to an extent that many of the psychiatric nursing respondents held no objection to marrying ex-psychiatric patients. Some authors ${ }^{12,13}$ have claimed that respondents who had good contact with mentally ill persons held more positive enlightened views towards such persons than those who did not. However, some other later authors held contrary opinions about the effect of contact on respondents' attitude towards mentally ill people. ${ }^{7,14}$ The effect of contact with a mentally ill person depends on the nature of the contact, the nature of the illness ${ }^{15}$ and the timing of the contact in the staging of illness. It is possible that the teachers in this study who presumably either have been exposed to mentally ill or treated mentally ill persons in diverse situations will not have established such interaction in such a way that it would influence their attitude towards them. That more teachers who had stayed longer in practice perceived less of the former mentally ill persons being unpredictable might have been a factor that is related to these respondents' having possibly been in contact with mentally ill or treated mentally ill pupils or colleagues longer than those with fewer years of teaching experience. That better educated Nigerians are more liberal in their attitude towards mentally ill persons than less educated ones as claimed by Binitie. The finding of Odejide and Olatawura ${ }^{11}$ is probably weakly supported by the observation of more teachers with Master's qualification agreeing to employ former mentally ill persons as gardeners than those with Bachelors and N.C.E qualifications in this study. More so, a greater proportion ( 9 out 10 vs. 7 out of 10) of N.C.E than Master's qualified teachers respectively significantly would not agree to their child marrying a treated mentally ill person. Likewise, about 8 out of 10 teachers with Master's qualification felt treated mentally ill persons were predictable and 6 out of 8 of same group of respondents felt same people were not dangerous to other people in their surroundings. That higher level of educational qualification might have been in part associated with the above observation could be seen in the contrary responses to the above issues by about half and almost 7 in every 10 respectively of Bachelor's and N.C.E qualified teachers. This observation probably may not be fully interpreted based on Master's qualified teachers having more knowledge about mental health principles than those with lesser qualifications. Byrne ${ }^{16}$ in a study of a British populace showed that despite more than half of the study sample having had a fair knowledge of mental illness, the majority held negative attitudes towards mentally ill persons. Fear and avoidance of treated mentally ill persons was more among female respondents, a similar finding to Zohar ${ }^{17}$ who in a study of a sample of Israeli urban residents found that less women than men agreed to providing home care for the mentally ill. This is likely because in the African context, men should be apparently brave and less submissive towards aggression. This might be the reason for more female teacher respondents' rejection of having their child/children marrying a treated mentally ill person than their male colleagues.

\section{Limitations}

Despite several foreign studies on teachers' attitude to mental illness, there were no specific articles on Nigerian teachers found. Hence, studies on diverse population groups compared with the findings in the present study

The respondents, being enlightened might have given responses that should reflect their status thereby masking their actual attitude towards mental illness. However, this positive response effect could not have significantly influenced the outcome of the study.

An earlier study in Nigeria claimed regular contact with mentally ill persons by psychiatric nurses influenced their attitude positively to an extent of not minding marrying such persons. The effect of such similar regular contact by teachers' in Nigeria, remains inconclusive until the outcome of future studies on this issue are evaluated for a rational generalization, further similar studies on different population groups of teachers in the country are required.

\section{Conclusion}

The results indicated that years of teaching and educational qualifications did affect the teachers' attitude towards former mentally ill persons. The higher the respondents' educational qualification in teaching the more he/she would not mind employing such persons in menial domestic jobs. Likewise, more years of teaching related positively in not viewing mentally ill persons as unpredictable. Perhaps fear of the unknown contributed to the more stigmatizing attitude of the female respondents towards former mentally ill persons in such intimate affairs as letting their children marry them. Despite knowing somebody or having had contact with mentally ill persons, the majority of teachers still expressed negative opinions about the dangerousness and unpredictability of former mentally ill persons. As a result of this prejudice towards former mentally ill persons, the majority of teachers were willing to relate with them only in situations that did not warrant very close social contacts but were unwilling to interact with them in closer social situations such as in marriages and employment. The majority of the respondents did not agree with entrusting them with such sensitive jobs as military duties, being the head of state of the country or serving as a minister of education.

The results from this study lend support to the need for educational programmes on mental health principles for the teachers. Such educational programmes could be organised in the form of seminars and workshops. One of the targeted aims of the programmes should be to address the commonly held misconceptions about mentally ill persons being potentially violent and as such, being people to avoid. Organized educational programmes should work towards helping the respondents develop a strong sense of understanding, empathy, compassion and tolerance towards mentally ill/former mentally ill persons. Participants in such programmes should understand that mentally ill persons are not different from people with such chronic physical health problems such as diabetes, hypertension or heart diseases. They should understand that with advances in treatment of mental health problems and community support, many former mentally ill persons could live fulfilled lives and contribute to the progress of their community. It is recommended that educational programmes on mental health should involve strategies that would encourage participants to develop a critical thinking ability towards media messages and their preconceptions about mental illness as a way of possibly influencing their negative impressions and attitudes towards 
former mentally persons. A combination of education and face- to - face interaction (as is presently done in campaigns against stigma towards people living with HIVAIDS) ${ }^{18}$ with mentally illfformer mentally ill persors could have a greater impact on changing attitudes than using either strategy in isolation. It is been suggested that meeting with willing and stable mentally ill persons who are proficient in their jobs and contribute to the life of their community, and attendance at mental health workshops might help in diminishing the negative attitudes and stereotypy towards mentallylformer mentally ill persons. Educational programmes on mental health issues for teachers without avenues for their interacting with sick mentally ill patients might not alter their entrenched views on the dangerousness of mentally ill persons. In the light of some limited reports about the dangerousness of mentally ill persons, incorporating visits to mental hospitals as part of the teachers' training might help in their understanding of how and when to actually see a mentally ill person as dangerous.

\section{References}

1. Binitie AO. Attitudes of educated Nigerians to psychiatric illness. Acta Psychiatrica Scandinavia 1970; 46:391-398.

2. Awaritefe A, Ebie JC. Contemporary attitudes to mental illness in Nigeria. African journal of Psychiatry 1975; $1: 37-43$

3. Corrigan P, Penn DL. Lessons from Social Psychology on discrediting Psychiatric stigma. American Psychologist 1999; 54: 765-776.

4. Bar-Levav R. The stigma of seeing a psychiatrist. American Journal of Psychotherapy 1976; 30: 3. 473-482.

5. Satorius N. Stigma: what can psychiatrists do about it? The Lancet 1997; (352) $9133:$ 1058-59.

6. Crisp AH, Gelder MG, Rix S, Howard I, Meltzer, Rowlands OJ. Stigmatization of people with mental illness. British Journal of
Psychiatry 2000; 177: 4-7.

7. Jegede RO. A Model of Mental Health Services for Nigerian School Children. African Journal of Psychiatry 1978; 1: 43-48.

8. Lemeshow S, Hosmer DW, Klar J, Lwanga SK. Adequacy of sample size in Health studies. World Health Organization; 1990.

Lawanga $S$, Lemeshaw S. Sample size determination in health studies: $A$ practical manual. Geneva, Switzerland: World Health Organization; 1991.

9. Wayne W.D. Biostatistics: A Foundation for Analysis in the Health Sciences, Textbook and student solutions manual, 8th edition.

10. Dean AG, Burton AH, Dicker RC. Epi Info Version 6. A Word Processing, Database and Statistics Programme for Epidemiology on Microcomputers, USD Inc., Stone Mountain, G.A; 1998.

11. Odejide $A O$, Olatawura $M O$. A survey of community attitudes to the concepts and treatment of mental illness in Ibadan, Nigeria. Nigerian Medical Journal 1979; 9: 343-347.

12. Corrigan PW, River LP, Lundin RK, Penn DL, Uphoff-Wasowski K, Campion J, et al. Three strategies for changing attributions about severe mental illness. Schizophrenia Bulletin 2001; 27: 187-195.

13. Martin JL, Romans SE. A community's attitude towards the mentally ill. New Zealand Medical Journal 1995; 108: 505-508.

14. Al-Adawi S, Dorvio AS, Al-Ismaily SS, Al-Ghafry DA, Al-Noobi BZ, AlSalami $A$, et al. Perception of and attitude towards mental illness in Oman 2002; 48: 305-317.

15. James A. Stigma of mental illness: Foreword. Lancet 1998; (352): 1048.

16. Byrne P. Reading about Psychiatric stigma. British Journal of Psychiatry 1997; 178: 281-284.

17. Zohar M, Floro F, Modan B. Attitudes towards Mental diseases in a sample of Israeli urban residents. Medica' Care 1978; 16: 426-432

18. Brown L, Trujillo L, Macintyre $K$. Interventions to reduce HIV/AIDS stigma: What have we learned? Horizons program and Tulane University 2001; $1-40$ 